\section{The Number of Emitters Alters Salt Distribution and Root Growth in Potted Gerbera}

\author{
Raquel Valdés', Julián Miralles, Jesús Ochoa, and Sebastián Bañón \\ Universidad Politécnica de Cartagena, Escuela Técnica Superior de \\ Ingeniería Agronómica, Departamento de Producción Vegetal, Paseo \\ Alfonso XIII, 48, 30203 Cartagena, Murcia, Spain \\ María Jesús Sánchez-Blanco \\ Departamento de Riego, Centro de Edafología y Biología Aplicada del \\ Segura (CEBAS-CSIC), P.O. Box 164, 30100 Espinardo, Murcia, Spain
}

Additional index words. coconut fiber, electrical conductivity, floriculture, irrigation, salinity

Abstract. Potted gerberas were grown in a greenhouse with one, two, or four emitters $\left(1.2 \mathrm{~L} \cdot \mathrm{h}^{-1}\right)$ per pot and irrigated with water of two levels of salinity $\left(1.5 \mathrm{dS} \cdot \mathrm{m}^{-1}\right.$ and $\left.3 \mathrm{dS} \cdot \mathrm{m}^{-1}\right)$. All pots received the same volume of water. The aim was to determine whether the number of emitters per pot affects the distribution of roots and salts in the substrate $(\mathbf{1 0 0} \%$ coconut fiber). We determined the electrical conductivity (EC) distribution at three different heights (upper, middle, and lower). We also studied the roots and EC horizontal distribution in four quadrants (southeast, southwest, northwest, and northeast). Shoot growth, leaf damage, plant water status, and photochemical capacity of photosystem II were also studied. Two or four emitters per pot reduced the leaching fraction compared with that observed with one emitter, improving both the amount and homogeneity of substrate moisture. In the two saline conditions used, the salt concentration in the substrate was irregular both vertically and horizontally, and the presence of roots in the horizontal quadrant sides was heterogeneous. Both of these behaviors decreased as the number of emitters per pot increased. Root growth was weakly related with the soluble salt content in the root zone. When saline water is used, two emitters per pot are to be recommended because the difference between using two and four emitters was very slight. The use of only one emitter reduced shoot and root growth and encouraged salt damage to leaves.

Irrigating with saline water leads to the accumulation of salt in the root zone, which reduces plant size and growth, alters plant development, and causes leaf damage. These effects are more pronounced in containergrown crops, in which the growing medium is more limited than in the ground, and, as a result, the aesthetic value of ornamental plants is reduced.

Over the last 25 years, numerous studies have been conducted to improve the irrigation of potted plants. Many of these studies have focused on the effects of different irrigation methods and systems on the accumulation and distribution of salts and roots in the more common substrates, taking into consideration different fertilizer sources and rates (Argo and Biernbaum, 1994, 1995; Morvant et al., 1997). Progress has also been made in scheduling irrigation (Million et al., 2007); however, few studies have compared

Received for publication 19 Aug. 2013. Accepted for publication 25 Nov. 2013.

We are grateful for the financial aid received from the Ministerio de Economía y Competitividad and FEDER through the projects (AGL2011-30022-C02-1 and AGL2011-30022-C02-2).

${ }^{1}$ To whom reprint requests should be addressed; e-mail raquel.valdes@upct.es. different ways of applying water over the surface of the substrate. Drip irrigation is generally thought to be a very efficient irrigation technique (Wang et al., 2011) and is the most widely used method for potted plant production. The basic concept underlying drip irrigation is to keep a bulb of soil moist so that roots can absorb water. The volume and shape of the wet bulb irrigated by each emitter are a function of the characteristics of the substrate (texture and hydraulic conductivity) and the discharge rate of the emitter (Awulachew et al., 2009). However, the number of water emission points over the substrate surface may also have an influence. Drip irrigation usually uses one emitter per pot for small containers, and very few published papers have studied the effect on growth and variations of roots and salts in the root ball when two or more emitters per pot are used. Ondrasek et al. (2008) reported the position of moisture and salt distribution in the substrate.

Our hypothesis was that applying the same volume of water to pots using more than one emitter may influence the retention and diffusion of moisture in the substrate and, as a consequence, the distribution of salts and roots. To verify this, coconut fiber-grown gerbera were irrigated with one, two, and four emitters per pot under two levels of the emitters in the pot could strongly affect the salinity (control or saline irrigation) during a spring-summer growing season determining the effects on substrate and leachate EC, root growth, shoot growth, leaf damage, plant physiological status, and leaching fraction.

\section{Materials and Methods}

Plant material and growing conditions. Seedlings of Gerbera hybrid cv. Triana were transplanted into $3.75-\mathrm{L}$ pots $(20-\mathrm{cm}$ upper internal diameter and height $18 \mathrm{~cm}$ ) containing 100\% coconut fiber substrate (Projar Professional Cocopeat; Projar, S.A. Valencia, Spain). The substrate fill height was $16 \mathrm{~cm}$. The experiment took place in a greenhouse with a semicircular cover $(12 \mathrm{~m}$ length $\times 7 \mathrm{~m}$ width, $3 \mathrm{~m}$ height at the side, and $4.5 \mathrm{~m}$ at the center) located at the Agricultural Experimental Station of the Polytechnic University of Cartagena (Cartagena, Spain). The top part was covered with polyethylene (PE) film and green shading screen ( $50 \%$ shade). The sides were covered with PE film and antiaphid mesh; the PE film could be rolled up for ventilation. The front and the back were covered with antiaphid mesh. The pots were introduced into white pots $(\phi 24 \mathrm{~cm})$ kept in place in holes $(21 \mathrm{~cm} \times 21 \mathrm{~cm})$ in a metal grid made of corrugated bars ( $8 \mathrm{~mm}$ diameter), $80 \mathrm{~cm}$ off the ground. This experiment was conducted from the first week of Mar. 2012 to the second week of Sept. 2012.

The irrigation system used pressurecompensating and antidrain emitters, which emit 1.2 L of solution per hour (Netafim Ltd. Corporate Headquarters, Tel Aviv, Israel). The emitters used were tested for homogeneity before the experiment started (the water flow varied between 1.16 and $\left.1.24 \mathrm{~L} \cdot \mathrm{h}^{-1}\right)$. The emitters were attached to a tube $(60 \mathrm{~cm} \times$ $4 \mathrm{~mm}$ ) and were inserted into the substrate by means of a plastic straight arrow. The irrigation system was controlled by a system similar to that described by Nemali and van Iersel (2006) but using a CR1000 data logger, which controlled the water pumps through an Agrónic 4000 (Sistemes Electrònics PROGRÉS, S. A., Bellpuig, Spain). The pumps were connected to $250-\mathrm{L}$ tanks containing the irrigation solutions. The soil moisture level was measured by an EC5 Soil Moisture Probe (Decagon Devices, Ltd., Pullman, WA) placed in the east-facing part of the substrate at an angle of $\approx 45^{\circ}$, with the flat side perpendicular to the surface of the substrate. The data logger was programmed to collect data every minute from three EC5 probes per treatment and to calculate the average every $30 \mathrm{~min}$. The $\theta$ was obtained from the voltage readings of the soil moisture sensor using our own substrate-specific calibration $\left(\theta=3.6642 * \mathrm{mV}-0.355 ; r^{2}=0.98\right)$ determined using the procedure described by Valdés et al. (2012). Fertilization was carried out by the irrigation head, and in all treatments, nutrients were provided at constant concentrations in the irrigation water, containing $80 \mathrm{~N}-17.5 \mathrm{P}-66.4 \mathrm{~K}(\mathrm{ppm})$ at $\mathrm{pH} 6$. This nutrient solution was made by mixing $\mathrm{KNO}_{3}, \mathrm{NH}_{4} \mathrm{NO}_{3}, \mathrm{~K}_{2} \mathrm{HPO}_{4}$, and $\mathrm{HNO}_{3}$. The 
addition of fertilizers increased the EC by $\approx 0.5 \mathrm{dS} \cdot \mathrm{m}^{-1}$.

The temperature and relative humidity were measured continuously during the experiment by a data logger (HOBO H08-00402; MicroDAQ.com, Ltd., Contoocook, NH). The average air temperature in the greenhouse was $8.3{ }^{\circ} \mathrm{C}$ (minimum), $25.7^{\circ} \mathrm{C}$ (average), and $45.2{ }^{\circ} \mathrm{C}$ (maximum); minimum relative humidity was $22.4 \%$ and the maximum $100 \%$ with a mean of $65.5 \%$.

Irrigation treatments. Six treatments resulted from irrigating with one, two, or four emitters per pot under non-saline $\left(1.5 \mathrm{dS} \cdot \mathrm{m}^{-1}\right)$ and saline conditions $\left(3 \mathrm{dS} \cdot \mathrm{m}^{-1}\right)$. The emitters were inserted in the center of the upper part of the four quadrants of the top circle of substrate [southeast (SE), southwest (SW), northwest (NW), and northeast (NE)]. When only one emitter was used, it was placed in the SE quadrant; when two emitters were used, they were placed in the SE and NW quadrants. In the case of four emitters, they were placed in each of the four quadrants. The treatments started the first week of Apr. 2012 (4 weeks after transplant, when the establishment phase had finished). Salinity took the form of sodium chloride added to the base nutrient solution of each tank.

For all treatments, the irrigation system was triggered when the average $\theta$ of the treatment with one emitter and $1.5 \mathrm{dS} \cdot \mathrm{m}^{-1}$ reached the threshold of $40 \%$ by volume. Hence, the irrigation frequency was the same for all treatments. All irrigation treatments were based on this treatment because it is the most frequently used. Furthermore, we started with the hypothesis that saline irrigation would increase the leaching fraction (as a result of the decrease in water consumption by the plant), whereas any increase in the number of emitters would increase consumption (wetter substrate), which would lead to an intermediate level of leaching.

The volume of water applied in each irrigation event was based on the duration of the event, which, in the case of one emitter, produced a leaching fraction of $\approx 15 \%$ at $\mathrm{EC}$ $1.5 \mathrm{dS} \cdot \mathrm{m}^{-1}$ (a normal leaching fraction in this treatment). The irrigations carried out with two emitters lasted half of the time used for one emitter and when four emitters were used the time was a quarter of the time used for one emitter.

Water consumption was calculated by measuring the water applied to the pots, so that in each treatment, three $1.5-\mathrm{L}$ plastic bottles containing the emitter or emitters were used.

From time to time, the volume of water collected in the bottles was measured in each treatment, and the sum of all these measurements was taken as the total amount of water applied. The mean quantity of water applied in the six treatments was $50.31 \pm 1.08 \mathrm{~L}$ per pot, which is slightly below the theoretical consumption calculated for the number of irrigation events and the duration of the same (50.67 L).

Measurements. The leaching fraction and leachate $\mathrm{EC}$ were measured in five pots of each treatment. The leachate was collected weekly throughout the study period in plastic containers and measured gravimetrically. The leachate EC was measured immediately after collection using an EC meter (Dist ${ }^{\circledR}$ 6; Hanna Instruments S.L., Eibar, Spain). The leaching fraction was quantified as the volume of solution leached from the pot divided by the total solution applied.

At the end of the experiment, the shoot growth, root growth, and leaf damage were determined in six plants per treatment. To calculate the shoot dry weight (DW), the plant parts were placed in a natural convection bacteriological oven (Model 2002471; JP Selecta SA, Barcelona, Spain) at $60{ }^{\circ} \mathrm{C}$ until constant weight was reached. Finally, the dry weight was determined by weighing with a GRAM ST precision balance (sensitivity of $10 \mathrm{mg}$ up to $1200 \mathrm{~g}$; Gram Precision SL, Barcelona, Spain). The root growth index (RGI) was calculated as a percentage of roots for each one of the four quadrant sides of the root ball. Four photographs were taken of the plant roots, and the percentage of root area in the root ball sides (horizontal quadrants) was calculated with the image analysis software for plant disease quantification ASSESS 2.0 (University of Manitoba, Winnipeg, Canada). To evaluate the damage caused by leaf necrosis, a leaf damage index (LDI) was adapted to the damage observed in the experiment. The LDI was calculated as the number of leaves with blades burned $25 \%$ to $75 \%$ multiplied by 0.5 plus the number of leaves with blades burned more than $75 \%$, dividing the result by the total number of leaves. Before choosing this index, we checked that its application to our plants properly reflected the level of salt damage in the leaves of several treatments.

To ascertain the physiological status of plants, the leaf water potential $\left(\Psi_{1}\right)$, osmotic potential $\left(\Psi_{\mathrm{o}}\right)$ and pressure potential $\left(\Psi_{\mathrm{p}}\right)$, net photosynthesis rate $\left(P_{\mathrm{n}}\right)$, and chlorophyll fluorescence were measured. $\Psi_{1}$ was estimated using a Scholander pressure chamber (Soil Moisture Equipment Co, Santa Barbara, CA), for which leaves were enclosed in a plastic bag and sealed in the chamber within $20 \mathrm{~s}$ of collection and pressurized at a rate of $0.02 \mathrm{MPa} \cdot \mathrm{s}^{-1}$. Leaves from the $\Psi_{1}$ measurements were frozen in liquid nitrogen $\left(-170^{\circ} \mathrm{C}\right)$ and stored at $-30{ }^{\circ} \mathrm{C}$. After thawing, the sap was extracted from the sample by means of a small press and placed on a filter paper disc in the osmometer chamber and $\Psi_{\mathrm{o}}$ values were measured using a WESCOR 5520 vapor pressure Osmometer (Wescor Inc., Logan, UT). $\Psi_{\mathrm{p}}$ was estimated as the difference between $\Psi_{1}$ and $\Psi_{0}$ for each time. The net photosynthesis rate was measured using a CIRAS-2 Portable Photosynthesis System (PP Systems, Amesbury, MA). The air flow rate through the cuvette was $200 \mathrm{~mL} \cdot \mathrm{min}^{-1}$ with a $\left[\mathrm{CO}_{2}\right]$ of $350 \mu \mathrm{mol} \cdot \mathrm{mol}^{-1}$, the air temperature was $20{ }^{\circ} \mathrm{C}$, the vapor pressure deficit was $1.6 \mathrm{kPa}$, and the photosynthetic photon flux $1500 \mu \mathrm{mol} \cdot \mathrm{m}^{-2} \cdot \mathrm{s}^{-1}$. Chlorophyll fluorescence was measured using a Pulse Modulated Fluorimeter FMS-2 (Gomensoro Scientific Instrumentation, S.A., Madrid,
Spain). The method and parameters determined were those described by Miralles et al. (2011). All physiological measurements were taken at midday in six plants per treatment at the end of the experiment.

Distribution of salt and $\mathrm{pH}$ in substrate. At the end of the experiment, the shoot of the plant was removed, and the pot and root ball were placed in a horizontal freezer (Zanussi ZFC639WAP; Electrolux Home Products, Madrid, Spain). After $24 \mathrm{~h}$ at $-25^{\circ} \mathrm{C}$ the root balls were taken out and sliced into upper, middle, and lower thirds. Each third was divided into four parts according to horizontal orientation: SE, SW, NW, and NE, resulting in a total of 12 pieces per root ball. The frozen root ball was then cut with a toothed saw. Each piece was saturated with distilled water, from which the major roots were removed, according to Camberato et al. (2009). After extraction, the $\mathrm{EC}$ and $\mathrm{pH}$ of the extract were measured using multirange equipment (Hanna Instruments $8633 \mathrm{~N}$ ) and with a portable pH-meter (Hanna Instruments 98150). Three measurements were made for each piece, and four root balls were used from each treatment.

Statistical analysis and experimental design. The experimental design was a randomized complete block with two blocks of 10 plants per treatment. In each treatment, one pot (or plant) was a replicate. A two-way analysis of variance (ANOVA) was used to test the effects of two factors (water salinity and the number of emitters per pot) and their interaction on the parameters studied. When interaction between factors was significant, a one-way ANOVA was used for each factor. Means were separated by the least significant difference test at $P<0.05$. All statistical analyses were performed using Statgraphics Plus for Windows (Manugistics Inc., Rockville, MD). A regression analysis was made between RGI and substrate EC using SigmaPlot 10.0 (Systat Software Inc., San Jose, CA). Ratios and percentages were arcsine $(\mathrm{x})^{1 / 2}$ transformed before statistical analysis to ensure homogeneity of variance.

\section{Results and Discussion}

Shoot growth, leaf damage, and number of inflorescences. The ANOVA applied to the shoot DW and LDI pointed to a significant relationship between salinity and the number of emitters per pot, indicating that the response to emitter treatments differed for the two saline conditions studied (Table 1). However, a non-significant interaction between salinity and the number of emitters in the number of inflorescences per plant was observed. The number of emitters did not alter the shoot DW of the plants in the control conditions; however, using two or four emitters per pot increased shoot DW in saline conditions by $\approx 12 \%$ compared with one emitter (Table 1). The saline treatment reduced the shoot DW compared with the control. The gerbera plants irrigated with saline solution had higher LDI scores than those irrigated with control water (Table 1), 
diminishing their visual quality. Two and four emitters per pot reduced the negative effect of salinity on leaves (necrosis). No factor produced statistically significant changes in the number of inflorescences per plant, averaging approximately seven in all treatments (Table 2).

Plant physiological status. Plant physiological status was assessed by determining the water relations and photochemical capacity. All plants presented a high midday leaf water potential value, which indicates that they were well watered and that there were no osmotic effects (Table 2). Increased salinity of the irrigation water generally leads to lower leaf osmotic potentials (Niu and Cabrera, 2010), as was observed in our experiment (Table 2). A common effect of a decrease in leaf osmotic potential is an increase in leaf turgor in saline conditions (Cassaniti et al., 2012). In our case, salinized plants had a higher leaf turgor potential than the control plants, but, despite this, they showed only a slight reduction in shoot growth (Table 1). Salinity invariably leads to increased concentrations of some ions in the shoots of plants, which may directly affect plant growth through an osmotic effect (not observed in our plants). Regarding the effect of the number of emitters per pot, only the use of four emitters caused a very slight increase in leaf water potential $(0.05 \mathrm{MPa})$,

Table 1. Effects of salinity and the number of emitters per pot on the parameters studied when the interaction was significant. ${ }^{z}$

\begin{tabular}{llccc}
\hline & & \multicolumn{3}{c}{ Number of emitters per pot } \\
\cline { 2 - 5 } Parameters & Salinity & 1 & 2 & 4 \\
\hline Shoot DW $(\mathrm{g})$ & Control & $66.61 \mathrm{a}$ & $65.49 \mathrm{a}$ & $68.14 \mathrm{a}$ \\
& Saline & $51.29 \mathrm{a}^{\mathrm{y}}$ & $58.49 \mathrm{~b}^{\mathrm{y}}$ & $57.90 \mathrm{~b}^{\mathrm{y}}$ \\
Leaf damage index & Control & $14.36 \mathrm{a}$ & $15.12 \mathrm{a}$ & $15.72 \mathrm{a}$ \\
& Saline & $30.09 \mathrm{~b}^{\mathrm{y}}$ & $24.83 \mathrm{a}^{\mathrm{y}}$ & $25.98 \mathrm{a}^{\mathrm{y}}$ \\
NPQ & Control & $1.50 \mathrm{a}$ & $1.56 \mathrm{a}$ & $1.50 \mathrm{a}$ \\
& Saline & $2.01 \mathrm{~b}^{\mathrm{y}}$ & $1.68 \mathrm{a}^{\mathrm{y}}$ & $1.69 \mathrm{a}^{\mathrm{y}}$ \\
Leachate EC $\left(\mathrm{dS} \cdot \mathrm{m}^{-1}\right)$ & Control & $2.05 \mathrm{a}$ & $4.02 \mathrm{~b}$ & $4.95 \mathrm{~b}$ \\
& Saline & $5.48 \mathrm{a}^{\mathrm{y}}$ & $12.63 \mathrm{~b}^{\mathrm{y}}$ & $13.86 \mathrm{~b}^{\mathrm{y}}$ \\
Substrate EC $\left(\mathrm{dS} \cdot \mathrm{m}^{-1}\right)$ & Control & $6.84 \mathrm{a}$ & $6.06 \mathrm{a}$ & $6.55 \mathrm{a}$ \\
& Saline & $13.48 \mathrm{~b}^{\mathrm{y}}$ & $9.94 \mathrm{a}^{\mathrm{y}}$ & $10.19 \mathrm{a}^{\mathrm{y}}$ \\
Root growth index $(\%)$ & Control & $19.89 \mathrm{a}$ & $21.81 \mathrm{~b}$ & $25.42 \mathrm{~b}$ \\
& Saline & $12.51 \mathrm{a}^{\mathrm{y}}$ & $16.56 \mathrm{~b}^{\mathrm{y}}$ & $24.31 \mathrm{c}$ \\
\hline
\end{tabular}

${ }^{\mathrm{z}}$ Control $\left(1.5 \mathrm{dS} \cdot \mathrm{m}^{-1}\right)$, saline $\left(3 \mathrm{dS} \cdot \mathrm{m}^{-1}\right)$.

y Significant differences between the two levels of salinity, and different letters indicate significant differences among the number of emitters by least significant difference test $(P<0.05)$.

$\mathrm{NPQ}=$ non-photochemical quencing; $\mathrm{DW}=$ dry weight; $\mathrm{EC}=$ electrical conductivity.

Table 2. Effects of salinity and the number of emitters per pot on the parameters studied when the interaction between both factors was not significant. ${ }^{\mathrm{z}}$

\begin{tabular}{|c|c|c|c|c|c|}
\hline \multirow[b]{2}{*}{ Parameters } & \multicolumn{3}{|c|}{ Number of emitters per pot } & \multicolumn{2}{|c|}{ Salinity } \\
\hline & 1 & 2 & 4 & Control & Saline \\
\hline Inflorescences per plant & $7.17 \mathrm{a}^{\mathrm{y}}$ & $7.50 \mathrm{a}$ & $6.67 \mathrm{a}$ & $7.45 \mathrm{a}$ & $6.78 \mathrm{a}$ \\
\hline Leaf water potential (MPa) & $-0.44 \mathrm{~b}$ & $-0.45 b$ & $-0.40 \mathrm{a}$ & $-0.47 \mathrm{a}$ & $-0.39 \mathrm{~b}$ \\
\hline Leaf osmotic potential (MPa) & $-1.51 \mathrm{a}$ & $-1.52 \mathrm{a}$ & $-1.50 \mathrm{a}$ & $-1.42 \mathrm{~b}$ & $-1.59 \mathrm{a}$ \\
\hline Leaf turgor potential (MPa) & $1.07 \mathrm{a}$ & $1.07 \mathrm{a}$ & $1.10 \mathrm{a}$ & $0.95 \mathrm{a}$ & $1.21 \mathrm{~b}$ \\
\hline $\mathrm{Fv} / \mathrm{Fm}$ & $0.85 \mathrm{a}$ & $0.85 \mathrm{a}$ & $0.86 \mathrm{a}$ & $0.85 \mathrm{a}$ & $0.85 \mathrm{a}$ \\
\hline $\mathrm{ETR} / P_{\mathrm{n}}$ & $16.21 \mathrm{a}$ & $15.77 \mathrm{a}$ & $15.02 \mathrm{a}$ & $15.55 \mathrm{a}$ & $15.79 \mathrm{a}$ \\
\hline Leaching fraction (\%) & $21.19 \mathrm{~b}$ & $10.44 \mathrm{a}$ & $9.60 \mathrm{a}$ & $9.94 \mathrm{a}$ & $17.54 \mathrm{~b}$ \\
\hline Substrate $\mathrm{pH}$ & $5.72 \mathrm{a}$ & $5.60 \mathrm{a}$ & $5.50 \mathrm{a}$ & $5.70 \mathrm{a}$ & $5.51 \mathrm{a}$ \\
\hline
\end{tabular}

${ }^{2}$ Control $\left(1.5 \mathrm{dS} \cdot \mathrm{m}^{-1}\right)$, saline $\left(3 \mathrm{dS} \cdot \mathrm{m}^{-1}\right)$. The maximum quantum efficiency of photosystem II $(\mathrm{Fv} / \mathrm{Fm})$ The ratio between the apparent electron transport rate and net photosynthesis $\left(\mathrm{ETR} / P_{\mathrm{n}}\right)$.

${ }^{y}$ Different letters indicate significant differences among the number of emitters per pot and between the two levels of salinity by least significant difference test $(P<0.05)$. teraction). Irrigating with two or four emitters per pot decreased leaching by approximately half compared with one emitter (Table 2), whereas these two treatments caused similar leaching fraction. So, irrigation with two or four emitters led to a higher degree of water retention in the substrate, which implies greater homogeneity of the substrate water content than was obtained with one emitter. Leachate EC was significantly affected by the number of emitters per pot and salinity. Using two and four emitters per pot significantly increased leachate EC compared with the values obtained with one emitter (Table 1), especially in the saline treatment (significant interaction). Two and four emitters per pot had similar effects on leachate EC (Table 1). The greater leachate EC under two and four emitters seems to have been more related with the EC of the water applied and with the volume of water leached than with the growth of plants (leaf biomass) because substrate moisture at the time of irrigation was nearly always higher in these treatments than in the one emitter treatment (data not shown). Greater salinity implies greater leachate EC, as occurred here. Regarding the volume of water leached, this was lower with two or four emitters as a result of the greater uniformity of substrate humidity. However, one emitter produced more concentrated salts around the emitter influence zone (Fig. 1CD) and in the whole substrate (Table 1). So, two or four emitters could flush out more salts than one emitter, leading to a degree of channeling and lower wettability of some parts of the substrate where salts are accumulated, and only the portion of substrate near the emitter would be properly flushed out.

Substrate EC and $p H$. Mean substrate EC $\left(E_{S}\right)$ significantly increased with salinity, whereas the opposite effect was observed as the number of emitters per pot increased, although this last effect was not observed when the plants were irrigated at $1.5 \mathrm{dS} \cdot \mathrm{m}^{-1}$ (interactive effect, see Table 1). Irrigating with two emitters per pot caused the same effects on substrate EC as irrigating with four (Table 1). These findings indicate the use of two or four emitters per pot encourages flushing out of the salts under saline conditions. We attribute this effect to the greater volume of substrate explored by the water applied because the water and salts extend more horizontally in a saturated substrate than in a drier substrate (De Rijck and Schrevens, 1998). Consequently, a lower leaching fraction implies a greater amount of salts, an effect confirmed by the EC values recorded in the leachate (Table 1).

To study the effect of the number of emitters on the distribution of salts in the whole substrate, a $\mathrm{CV}$ of the $\mathrm{EC}_{\mathrm{S}}$ was calculated among the 12 pieces extracted from each pot (Fig. 2). Overall, the salts were unevenly distributed in the substrate $(\mathrm{CV}$ $20 \%$ or greater). The control treatment led to a more heterogeneous distribution of salts than saline irrigation, except when four emitters per pot were used, because salt content 
variability in the root ball was attenuated by the number of emitters: the lower the salinity in the irrigation water, the greater the attenuation attained by two or four emitters.

Salinity, the number of emitters per pot and their interaction had no significant effects on substrate $\mathrm{pH}$ (Table 2). However, $\mathrm{Ku}$ and Hershey (1991, 1992) found a vertical pH gradient in potted geranium and poinsettia, whereas De Rijck and Schrevens (1998) found very little variation in rockwool slabs. Any such variation is often associated with a lower $\mathrm{pH}$ in the bottom of the root ball and is encouraged by low water alkalinity and high amounts of ammonium fertilizer (Argo and Fisher, 2002). In our trial, all treatments had a substrate $\mathrm{pH}$ of $\approx 5.5$ (Table 2 ) as a result of the effect of the nitric acid $\left(\mathrm{HNO}_{3}\right)$, which was continuously added to lower the $\mathrm{pH}$ of the irrigation solution.

Vertical distribution of $E C_{S}$. On the whole, the $\mathrm{EC}_{\mathrm{S}}$ at the end of the experiment was highest in the top layer (Fig. 1A-B). Salt accumulation in the top part of the substrate is often associated with subirrigation than overhead irrigation (Kang and van Iersel, 2009; Rouphael and Colla, 2009). Other reports using drip irrigation showed the $\mathrm{EC}_{\mathrm{S}}$ to be higher in the upper layer than in the underlying layers (Ku and Hershey, 1992; Million et al., 2007; Morvant et al., 1997). In our case, increasing the number of emitters per pot slightly reduced the vertical stratification of salts in the substrate, probably because the up and down movement of water and salts was altered. This behavior was most evident under the control irrigation with four emitters per pot (Fig. 1A). The higher EC of the top layer may have been the result of evaporation between irrigation events because the evaporation of water from the substrate surface may be significant. Navarro et al. (2007) estimated that evaporation from the surface of the substrate in potted Arbutus unedo was $\approx 30 \%$ of evapotranspiration, and Biernbaum et al. (1991) found that $30 \%$ to $60 \%$ of total water lost from a potted plant was caused by evaporation from the substrate surface. Evaporation from the substrate surface leads to the accumulation of salts at the top of the pot (Guttormsen, 1969). In our experiment we used coconut fiber as a substrate, which has better capillarity than most other commonly used potting substrates (Krishnamurthy et al., 2009). Our previous observations indicated that the coconut fiber surface dries quickly, whereas the rest of the substrate remains wet. Probably, the wicking action of coconut fiber lifted moisture toward the higher part of the substrate, where evaporation was very rapid as a result of a high vapor pressure deficit (Rouphael and Colla, 2005). In this way, evaporation from the coconut fiber surface allowed salts to build up in the top part. Moreover, we used a drip irrigation system with emitters of $1.2 \mathrm{~L} \cdot \mathrm{h}^{-1}$ so that water percolated slowly to the deeper layers, decreasing the downward movement of the salts.

Horizontal distribution of $E C_{S}$. The analysis of the distribution of EC among

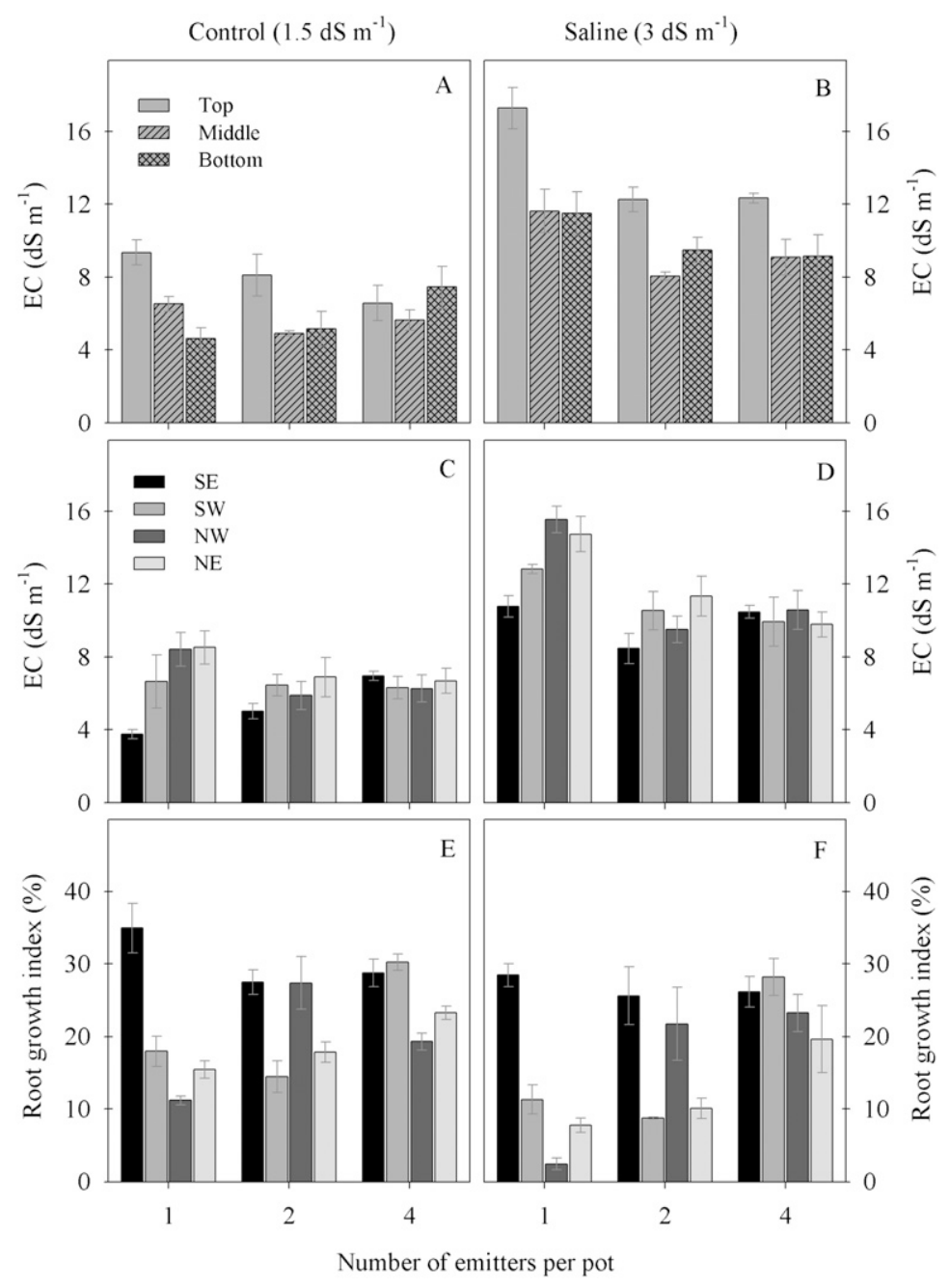

Fig. 1. Electrical conductivity (EC) and root distribution in the root ball. (A) Vertical EC gradient with an irrigation solution of $1.5 \mathrm{dS} \cdot \mathrm{m}^{-1} ;(\mathbf{B})$ vertical EC gradient with an irrigation solution of $\left.3 \mathrm{dS} \cdot \mathrm{m}^{-1} ; \mathbf{C}\right)$ horizontal EC gradient with an irrigation solution of $1.5 \mathrm{dS} \cdot \mathrm{m}^{-1} ;$ (D) horizontal EC gradient with an irrigation solution of $3 \mathrm{dS} \cdot \mathrm{m}^{-1} ;(\mathbf{E})$ horizontal root distribution with an irrigation solution of $1.5 \mathrm{dS} \cdot \mathrm{m}^{-1}$; (F) horizontal root distribution with an irrigation solution of $3 \mathrm{dS} \cdot \mathrm{m}^{-1}$. Vertical bars show least significant difference at $P<0.05$.

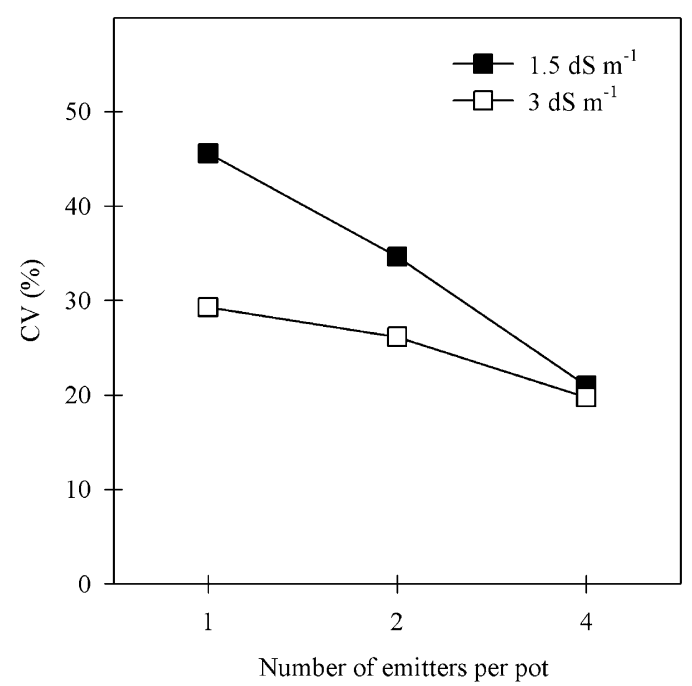

Fig. 2. $\mathrm{CV}$ of the substrate electrical conductivity (EC) in the root ball for the six treatments studied. 


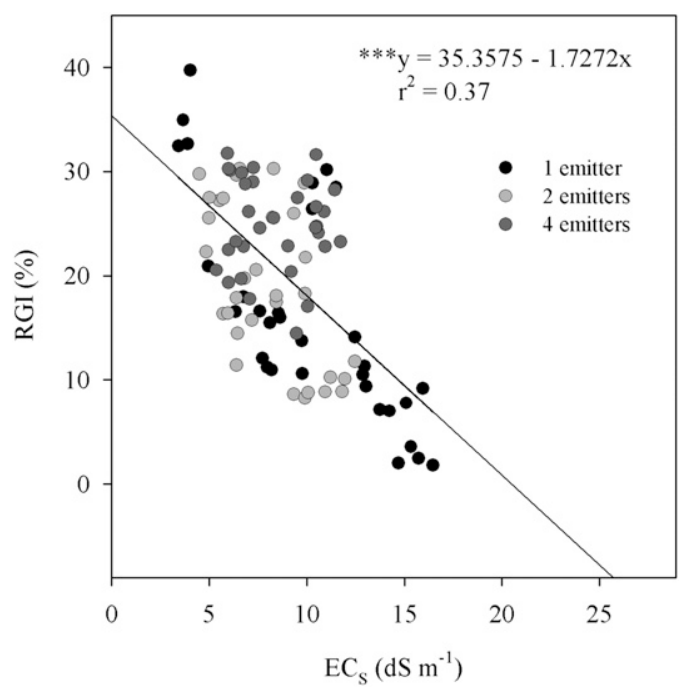

Fig. 3. Regression analysis between root growth index (RGI) and substrate electrical conductivity $\left(\mathrm{EC}_{\mathrm{S}}\right)$. Asterisks indicate statistical significance at the 0.001 level.

horizontal quadrants of the substrate (horizontal distribution) also showed a salt gradient. Irrigating with one emitter per pot led to the lowest $\mathrm{EC}_{\mathrm{S}}$ in the $\mathrm{SE}$ quadrant (Fig. $1 \mathrm{C}$ D), where the emitter was placed, building up a wet bulb in this quadrant. Because the wet bulb was often saturated, the irrigation solution spread more in the horizontal direction (De Rijck and Schrevens, 1998; Ondrasek et al., 2008), displacing salts to the other quadrants. This behavior was observed with one emitter under both saline conditions studied and was especially evident at 1.5 $\mathrm{dS} \cdot \mathrm{m}^{-1}$. The horizontal $\mathrm{EC}_{\mathrm{S}}$ gradient was decreased by increasing the number of emitters per pot independent of the level of salinity in the irrigation water. When two emitters per pot were used, the quadrants with an emitter tended to accumulate less salts than those without an emitter, whereas with four emitters per pot, all quadrants had a similar salt content (Fig. 1C-D).

Root growth and horizontal distribution of roots in root ball. The RGI of gerbera depended on the number of emitters per pot and salinity: the index was reduced by salinity, whereas the opposite occurred with the number of emitters per pot (Table 1). The interaction between salinity and the number of emitters was the result of salinity having no effect on RGI when four emitters per pot were used. Several authors have noted that high $\mathrm{EC}_{\mathrm{S}}$ may inhibit root growth with a reduction in the length and mass of roots (Argo and Biernbaum, 1995; Morvant et al., 1997; Shannon and Grieve, 1998). The ECs and RGI had a significant linear relationship (Fig. 3), suggesting that root growth was related to salt concentration in the root zone (RGI decreasing with increasing $\mathrm{EC}_{\mathrm{S}}$ ). However, this relationship was weak $\left(r^{2}=0.37\right)$ because of the influence of moisture (Santamaria et al., 2003) and temperature (Drennan and Nobel, 1996) on root growth in the substrate. We found that the salts accumulated in the top layer, whereas the greatest part of the gerbera root system was in the lower layer.

The horizontal distribution of roots in the root ball showed similar behavior with both irrigation treatments, especially when one emitter was used (Fig. 1E-F). With one emitter per pot, the RGI was highest in the SE quadrant (where the emitter was placed), intermediate in the SW and NE quadrants, and lowest in the NW quadrant (furthest from the emitter). In this case, the quadrant with the lowest EC had the highest root growth (Fig. 1C-E). When two emitters per pot were used, the SE and NW quadrants (wettest) had a higher RGI than the SW and NE quadrants (least wet). Using four emitters per pot (one in each quadrant), RGI was higher in the south than in the north (Fig. 1E-F), which could be related to the higher temperature in these quadrants (sunniest).

\section{Conclusions}

Using more than one emitter per pot attenuated both the reduced aerial growth and leaf necrosis caused by salinity; two and four emitters having the same effect with this respect. Irrigating with two or four emitters per pot decreased the salt content and improved substrate wetting. Increasing the number of emitters increased the homogeneity of salt distribution in the substrate, because salts tended to increase around the wet bulb produced by the emitter. The presence of roots at the root ball side was weakly related with the soluble salts content of the root zone; it seems likely that root growth was mainly determined by the moisture content of the root zone. The effectiveness of using two or four emitters per pot was more evident under saline conditions. Under the conditions used in this study, we recommend irrigating with two emitters per pot, especially when the irrigation solution is saline.

\section{Literature Cited}

Argo, W.R. and J.A. Biernbaum. 1994. Irrigation requirements, root-medium $\mathrm{pH}$, and nutrient concentrations of easter lilies grown in five peat-based media with and without an evaporation barrier. J. Amer. Soc. Hort. Sci. 119:11511156.

Argo, W.R. and J.A. Biernbaum. 1995. The effect of irrigation method, water-soluble fertilization, replant nutrient charge, and surface evaporation on early vegetative and root growth of poinsettia. J. Amer. Soc. Hort. Sci. 120:163169.

Argo, W.R. and P.R. Fisher. 2002. Understanding $\mathrm{pH}$ management for container-grown crops. Greenhouse Grower.

Awulachew, S.B., P. Lemperiere, and T. Tulu. 2009. Training manual on agricultural water management. Module 5: Irrigation methods. ILRI Publications Unit, Addis Ababa, Ethiopia.

Biernbaum, J.A., W. Argo, and M. Yelanich. 1991. Effect of a pot cover on irrigation and fertilizer requirements and media nutrient stratification. HortScience 26:764.

Camberato, D., R. Lopez, and M. Mickelbart. 2009. $\mathrm{pH}$ and electrical conductivity measurements in soilless substrates. Purdue Univ. Ext. Serv. Bul. HO 237-W:1-6.

Cassaniti, C., D. Romano, and T.J. Flowers. 2012 The response of ornamental plants to saline irrigation water, p. 131-158. In: García-Garizábal, I. and R. Abrahao (eds.). Ornamental plants to saline irrigation water. IN-TECH, Rijeka, Croatia.

De Rijck, G. and E. Schrevens. 1998. Distribution of nutrients and water in rockwool slabs. Sci. Hort. 72:277-285.

Dionisio-Sese, M. and S. Tobita. 2000. Effects of salinity on sodium content and photosynthetic responses of rice seedlings differing in salt tolerance. J. Plant Physiol. 157:54-58.

Drennan, P.M. and P.S. Nobel. 1996. Temperature influences on root growth for Encelia farinosa (Asteraceae), Pleuraphis rigida (Poaceae), and Agave deserti (Agavaceae) under current and doubled $\mathrm{CO}_{2}$ concentrations. Amer. J. Bot. 83:133-139.

Guttormsen, G. 1969. Accumulation of salts in the sub-irrigation of pot plants. Plant Soil 31:425438.

Kang, J.G. and M.W. van Iersel. 2009. Managing fertilization of bedding plants: A comparison of constant fertilizer concentrations versus constant leachate electrical conductivity. HortScience 44:151-156.

Krishnamurthy, K., C. Maheswari, R. Udayarani, and V. Gowtham. 2009. Design and fabrication of coir pith prequetting machine. World Appl. Sci. J. 7:552-558.

Ku, C.S. and D.R. Hershey. 1991. Leachate electrical conductivity and growth of potted poinsettia with leaching fractions of 0 to 0.4 . J. Amer. Soc. Hort. Sci. 116:802-806.

$\mathrm{Ku}$, C.S. and D.R. Hershey. 1992. Leachate electrical conductivity and growth of potted geranium with leaching fractions of 0 to 0.4 . J. Amer. Soc. Hort. Sci. 117:893-897.

Million, J., T. Yeager, and C. Larsen. 2007. Water use and fertilizer response of azalea using several no-leach irrigation methods. HortTechnology 17:21-25.

Miralles, J., J.A. Martínez, J.A. Franco, and S. Bañón. 2011. Determining freezing injury from changes in chlorophyll fluorescence in potted oleander plants. HortScience 46:895-900.

Morvant, J.K., J.M. Dole, and E. Allen. 1997. Irrigation systems alter distribution of roots, 
soluble salts, nitrogen, and $\mathrm{pH}$ in the root medium. HortTechnology 7:156-160.

Navarro, A., S. Bañon, E. Olmos, and M.J. Sánchez-Blanco. 2007. Effects of sodium chloride on water potential components, hydraulic conductivity, gas exchange and leaf ultrastructure of Arbutus unedo plants. Plant Sci. 172:473-480.

Nemali, K.S. and M.W. van Iersel. 2006. An automated system for controlling drought stress and irrigation in potted plants. Sci. Hort. 110: 292-297.

Niu, G. and R.I. Cabrera. 2010. Growth and physiological responses of landscape plants to saline water irrigation: A review. HortScience 45:1605-1609.
Ondrasek, G., D. Romic, M. Romic, F. Tomic, and I. Mustac. 2008. Salt distribution in peat substrate grown with melon (Cucumis melo L.). Acta Hort. 779:307-312.

Rouphael, Y. and G. Colla. 2005. Growth, yield, fruit quality and nutrient uptake of hydroponically cultivated zucchini squash as affected by irrigation systems and growing seasons. Sci. Hort. 105:177-195.

Rouphael, Y. and G. Colla. 2009. The influence of drip irrigation or subirrigation on zucchini squash grown in closed-loop substrate culture with high and low nutrient solution concentrations. HortScience 44:306-311.

Santamaria, P., G. Campanile, A. Parente, and A. Elia. 2003. Subirrigation vs drip-irrigation:
Effects on yield and quality of soilless grown cherry tomato. J. Hort. Sci. Biotechnol. 78:290296.

Shannon, M. and C. Grieve. 1998. Tolerance of vegetable crops to salinity. Sci. Hort. 78:5-38.

Valdés, R., J. Miralles, J. Ochoa, J.A. Franco, M.J. Sánchez-Blanco, and S. Bañón. 2012. Prueba de sondas para medir conductividad y humedad del sustrato en maceta en condiciones salinas. XI Simposio Hispano-Portugués de Relaciones Hídricas en las Plantas. Libro de actas 222225.

Wang, R., Y. Kang, S. Wan, W. Hu, S. Liu, and S. Liu. 2011. Salt distribution and the growth of cotton under different drip irrigation regimes in a saline area. Agr. Water Mgt. 100:58-69. 